\title{
Effectiveness of Jogging, Eye Movement Exercises, and Diaphragmatic Breathing in Reducing Migraine Symptoms: A Randomized Controlled Trial
}

Mohammad Dawood Rahimi ( $\sim$ dawoodrahimi@msn.com )

Ferdowsi University of Mashhad https://orcid.org/0000-0002-6282-1862

Fatemeh Alidoosti

Khayyam University

Pouriya Hassani

University of Padova School of Psychology: Universita degli Studi di Padova Scuola di Psicologia

Mohammad Mahdi Ghasemi

Mashhad University of Medical Sciences

Javad Salehi Fadardi

ferdowsi University of Mashhad

Research article

Keywords: Migraine treatment, jogging, eye movement exercises, diaphragmatic breathing

Posted Date: March 18th, 2021

DOI: https://doi.org/10.21203/rs.3.rs-309380/v1

License: (c) (i) This work is licensed under a Creative Commons Attribution 4.0 International License.

Read Full License 


\section{Abstract}

Background: electrophysiological dysresponsiveness (ED) is apparent in a migraine brain. Various methods have been suggested to regulate ED, including electrochemical transduction or regulation of Nitric Oxide (NO) and Brain-Derived Neurotrophic Factor (BDNF), jogging, eye movement exercises, and diaphragmatic breathing.

Objectives and methods: A three-group, double-blind, and randomized design with pre-test, post-test, and follow-up assessment was used to test the effectiveness of jogging, eye movement exercises, and diaphragmatic breathing in the treatment of patients with episodic migraine. International Classification of Headache Disorders 3rd edition (ICHD-3) was used to diagnose the migraine patients, who were randomly assigned to one of the three study groups to perform either 12 consecutive weeks of (a) jogging and eye movement exercises $(n=22) ;(b)$ jogging and diaphragmatic breathing ( $n=19)$; or (c) treatment as usual $(T A U)$, receiving prescribed medication $(n=22)$ group.

Results: The results of a series of MANCOVA showed that, compared to the TAU group, patients in the two experimental groups showed significant reductions in the frequency, duration, and intensity of their episodic migraine attacks. Moreover, the frequency of menstrual cycle-dependent headache attacks and over the counter drugs use were reduced, and the quality of sleep and drinking water were improved at post-test and a 12-month follow-up.

Conclusion: The results suggest that jogging and eye movement exercises or jogging and diaphragmatic breathing can be used as effective alternative interventions in the treatment of episodic migraine.

Trial registration retrospectively: Ir.mums.fm.rec.1396.362

\section{Introduction}

Dynamic dysfunctions within the pain matrix, abnormal modulation in pain circuits, altered pain inhibition, and electrophysiological dysresponsiveness (ED) hint a migraine brain (1-3). Moreover, the dysfunctions could be exacerbated by the reciprocal connectivity or bidirectional impacts of neural, endocrine, immune, and humoral alterations in response to daily life stressors. Examples of such links could be observed in the sensory dysfunction or metabolism dysregulation, specific spontaneous oscillations, and maladaptive stress responses in several networks of a migraine brain including hypothalamus and the brain stem (4). For instance, eye-brain electrochemical transduction and retinal nerve fiber alterations seem to play a key initiating role in a migraine brain (e.g., through choroidal thinning and thickening or retinal vasospasm) (5). As a state of hypoxia, these changes also appear to be initiated by Nitric Oxide (NO)-mediated vasodilator responses or by endothelin-1 (ET-1)-mediated vasoconstrictive responses in a migraine brain $(6,7)$. Furthermore, structural and functional abnormalities in the endothelial progenitor cells have been reported in patients with migraine (8). The domains or interlinks between mitochondrial energy production, reactive oxygen species (ROS) availability, and ion homeostasis (e.g., calcium influx) have been clearly shown in a migraine brain (9). 
Under these circumstances, ionic dysregulation (e.g., anoxic depolarization) appears to share several links with a hyperexcitable migraine brain (10). Therefore, depending on the quantity, duration, or presence of other elements, a biomolecule (e.g., NO or Brain-Derived Neurotrophic Factor; BDNF) can play various roles in these networks or domains. The key roles that NO plays in the brain consist of (a) regulating cerebral blood flow (CBF) or vascular tone; (b) modulating cells communications; and (c) acting as an antioxidant agent $(11,12)$. In addition, both NO and BDNF are pleiotropic and pain modulators $(13,14)$. Homeostatic dysregulation of these biomolecules during migraine attacks is another implication in the pathophysiology of the migraine disease $(15,16)$. Therefore, regulation and availability of NO or BDNF are essential during health and illness, including migraine attacks, as stressful insults to the brain $(17,18)$.

The regulation of NO or BDNF gene expression as a neuroprotective strategy appears to offer a promising method for decreasing the load of the insults. Although migraine-specific, antidepressants, and antiepileptic drugs directly target these types of expressions (because of similar molecular features of the drugs or identical structural features of the cells), most of these medications have drug-drug sharing and target-related induced undesirable side effects (11). Therefore, given the vital role of NO and BDNF biomolecules, the direct targeting of their expressions can have detrimental side effects both for brain function and vascular tone $(13,18,19)$. For example, in the presence of triptans or morphine, NO boosts the activation of trigeminal pathways or increases the risk of medication overuse headache $(\mathrm{MOH})(20$, 21). Another interesting instance of over-expression is the elevated level of BDNF. Interlinks of epilepsy, migraine, and neuronal hyperexcitability are obvious. Recent evidence suggests links between elevated levels of BDNF and neuronal hyperexcitability (22). Moreover, the upregulation of BDNF compensates for pain hypersensitivity (23). Nevertheless, the chronic administration or high doses of antidepressants suppress the expression of these biomolecule genes (24). Moreover, the manipulation of BDNF gene expression may contribute to the development of other diseases and disorders including anxiety, depression, or chronification of migraine (25). Considering these endogenous biomolecule deteriorations that are caused by direct-target interventions in a hypersensitive migraine brain, developing novel, safe, multidimensional, and non-direct or non-pharmacological interventions is vital to the treatment of a multifactorial disease like migraine (26).

Based on previous studies (27-29) that have shown the effect of regular aerobic exercises or progressive relaxation techniques on pain processing or migraine, the present study proposes that regular aerobic exercises relieve pain experience possibly through a cascade of facilitative mechanisms, including the reduction of N-Methyl-D-Aspartate (NMDA) receptors or regulation of serotonin or glutamate excitatory signaling (30-32). Moreover, NO inhibits the excess presence of NMDA receptors through using a positive feedback loop and facilitation of glial cells function, and hence regulates the excitotoxic effect of accumulative glutamate following a disease like migraine (33-35). In the same vein, regular exercise maintains the brain homeostasis and improves the brain function by promoting the gene expression of BDNF (36). Exercise-induced BDNF reduces excitotoxins through a negative feedback loop (37).

Therefore, as a regulator of homeostatic response, BDNF protects the brain against glutamate-induced toxicity during migraine attacks $(38-40)$. Furthermore, to regulate the hypoxia-induced alterations in a 
migraine brain (41), exercise-induced, nasal, or diaphragmatic breathing can offer a promising adjunctive method. By passing through nasal mucosa and influencing olfactory neuroepithelium receptors, the nasal breathing facilitates autonomic nervous system, hormonal systems, and psychological constructs, all of which are closely related to a migraine brain (42). Naturally, regular physical exercise improves nasal breathing (43). The visual exercise, through cortical re-arrangement and oscillatory feedback signaling between cranial motor nerves, brain stem, thalamus, hypothalamus, and motor cortex regulates local and cortical endothelium releasing factors including NO and BDNF (44-48). To conclude, regulating several reciprocal feedback mechanisms between neuronal and vascular interactions, including hormones (e.g., melatonin, irisin), biomolecules (e.g., No, and BDNF), organelles (e.g., mitochondria), axis (e.g., hypothalamus-pituitary-adrenal (PHA)), and systems (e.g., immune and metabolism), regular physical exercises or other progressive regulatory techniques including eye movement exercise and diaphragmatic breathing can alleviate pain processing in a migraine brain (49-54).

\section{Methods}

\section{Study population}

The present study was performed on 53 right-handed (55) Persian-speaking female patients $(56,57)$ (mean age $=31.19 ; S D=5.67$; range of $19-40)$ with episodic migraine $(33.3 \%$ with aura (MwA); $66.7 \%$ without aura (MwOA)) selected from a population of 764 patients with migraine who were admitted to several local state hospitals between September 2015 and August 2016. After eligibility assessment (the study flowchart below), 353 individuals did not meet the study criteria (below) and 276 were unwilling or unable to participate in the study. Another 72 participants were discontinued from the study for being unpunctual, and 10 were missed during the follow-up. Participation in the study was voluntary. During their enrolment, participants filled out a questionnaire on demographic information, history of migraine, socioeconomic status, and migraine type (Table 1). 
Table 1

Mean and SDs for demographic information, history of migraine, and distribution of participants based on socioeconomic status and type of migraine in study groups.



Inclusion criteria were (a) 18-50 years of age (58); (b) a confirmed diagnosis of episodic migraine based on the International Classification of Headache Disorders (ICHD) criteria (59); and (c) a history of migraine over the last 12 months regardless of the migraine type (i.e., with aura (MwA) or without aura $(M w O A))$. Exclusion criteria were (a) a history of any other neurological, gut, or respiratory-related diseases including concomitant diagnosis of other headache disorders especially medication overuse headache $(\mathrm{MOH})(60)$; (b) any kind of surgery that restricts their ability to jog, perform eye movement exercises, and/or breath; or (c) cardiovascular-related diseases, e.g., blood pressure abnormalities. The use of pain medication was allowed between post-test and the follow-up assessment for the patients in the control group. Patients in the experimental groups agreed not to take pain medications or any other interventions for at least three months in advance of and during the present study. However, if they were experiencing severe pain, they could use limited medication prescribed by their physician. Flowchart shows flow of the present study from 2016 to 2019.

\section{Experimental design}

The present study ( $3 \times 3$ factorial design; three groups and three dependent variables) is a randomized double-blind controlled trial that aimed to investigate whether jogging plus eye movement exercises or jogging plus diaphragmatic breathing could be effective in alleviating episodic migraine symptoms compared to a control group that use prescribed medications for migraine (treatment as usual). 
All of participants had to meet the inclusion criteria and be flexible about the terms of the study after their diagnosis was confirmed by two consultant neurologists at a local state hospital based on ICHD criteria (59). The sample was tested and selected over a 46-week period between August 2016 and July 2017. The sample was screened for frequency, duration, and intensity of attacks in the last three months. Next, participants were randomly (1:1:1) assigned to one of the experimental groups, i.e., eye movement exercises $(n=22)$ or diaphragmatic breathing $(n=19)$ or to the control group $(n=22)$. All the data were recorded by an experimenter who was blind to the study design. The data analysis was also conducted by one of the co-authors, who was blind to the study design and its hypotheses.

\section{Randomization procedure}

Because the present study was based on a double-blind design, clinicians, and experimenters who were working with the patients were not aware of the nature of the study design and procedures. Participants were informed only about what they were expected to do but not about their group allocation and other participants in the study, and the study design and goals. To reduce the risk of prediction for a sample size of $n>50$, we used telephone (secure) allocation of participants by an independent person in line with instructions for simple randomization method (61). Before proceeding to the next stage, the inclusion and exclusion criteria of the present study were monitored and checked. For example, if a participant was on a prescribed or non-prescribed medication, she was recommended to stop her medication in a tapering manner (i.e., over a 6-week period). Moreover, patients were monitored and screened for any types of smoking (e.g., the participants who smoked cigarettes were instructed to stop smoking; otherwise, they were excluded from the experiment). Smoking was discouraged to help with the patients' physical exercise routine.

A written informed consent was obtained from the participants.

The study was approved by the ethical committee of Mashhad University of Medical Sciences (Ir.mums.fm.rec.1396.362).

One experimenter was randomly assigned to each group to execute the participants' enrollment and interventions' assignments in each group during study. Experimenters were instructed and scheduled to monitor and record medications, menstrual cycles, sleeping, drinking water, and exercise intolerance behaviors in the experimental and control groups. The participants were told that their participation was voluntary, and they could withdraw from the experiment at their will. They were told that they are part of a study on the migraine. A written informed consent was obtained from the participants. The study was approved by the ethical committee of Mashhad University of Medical Sciences (Ir.mums.fm.rec.1396.362).

\section{Interventions}

\section{Jogging plus eye movement exercises or jogging plus diaphragmatic breathing instruction}


There were two experimental groups. The first experimental group performed jogging plus eye movement exercises. The second experimental group performed jogging plus diaphragmatic breathing instruction.

During the jogging, they were instructed to follow a breathing rhythm that required two relaxed, deep nasal inhalations, a repose, and two deep oral exhalations.

Jogging required circling around the outer ring of a local public park for $3.2 \mathrm{~km}(\approx 25-\mathrm{min})$. During the jogging, they were instructed to follow a breathing rhythm that required two relaxed, deep nasal inhalations, a repose, and two deep oral exhalations. The jogging was exercised every other day (between 5:00 p.m. and 7:00 p.m.) over a period of 12 weeks.

The eye movement exercises included horizontal (dextroversion / levoversion) and vertical (sursumduction / deorsumduction) conjugated eye movements (62). Participants performed a 5-min eye movement exercise 30-min before having their breakfast every morning and 30-min before going to bed at night for 12 weeks. The 5 -min bedtime phase was initiated by 15 -round movements of the right-hand index finger, followed by 15 -round left-hand index finger movements in the horizontal visual field, which was followed by the same procedure in the vertical visual field with a front-forward, fixed head with the eyes following the finger in a constantly controlled manner (Fig. 3). The 5-min morning phase was initiated, sustained, and terminated with the same procedure, but instead of moving the index finger in the visual field, the head was moved horizontally ( 30 rounds laterally) and then vertically ( 30 rounds up and down) with fixed eyes on a fixed index finger in the visual field (Fig. 4) $(63,64)$. Figures 2 and 3 show participants' hands and head-guided eye movement exercises in the experimental groups.

Participants were persuaded to focus on their breathing while inhaling and exhaling $(65,66)$.

The diaphragmatic breathing practice required a deep nasal inhalation, a two-second repose, and a long, deep oral exhalation three times a day around 7:00 a.m., 2:00 p.m., and 9:00 p.m. for 5-min for 12 consecutive weeks (Fig.

The diaphragmatic breathing practice required a deep nasal inhalation, a two-second repose, and a long, deep oral exhalation three times a day around 7:00 a.m., 2:00 p.m., and 9:00 p.m. for 5-min for 12 consecutive weeks (Fig. 2). Participants were persuaded to focus on their breathing while inhaling and exhaling $(65,66)$.

During the eye movement exercises and diaphragmatic breathing practice, participants were asked to sit in an upright position and plant their feet on the ground at a 90-degree angle to match the extension of their shoulders. Moreover, they were instructed to fix their head horizontally, leveled with their body. They were also asked to arch their back completely and slouch forward. The position was followed by rolling shoulders back and dropping them down. The preparation phase was ended by a deep breath and relaxation (Fig. 1) (67).

\section{Control group}

As stated before, the control group was receiving medical treatment as usual, which solely consisted of common prescribed medication to help with the migraine symptoms. Because there were a variety of 
prescribed medications and their effect on the migraine symptoms was not a goal of the present study, it was not necessary to keep a record of the type of medication that participants in the control group were using over the two-year of the present study. Therefore, we monitored this group of patients and like the experimental groups, we administered all the study measures with them at the baseline, post-test, and the follow-up assessments.

\section{Procedure}

However, none of the participants in the experimental groups reported referring to their physician or resuming the use of migraine prescribed or non-prescribed medication at any of phone calls or follow-up assessments.

The telephone calls also helped minimize the participants' dropouts.

Moreover, weekly telephone follow-ups were made to enquire about the participants' experiences of pain, use of prescribed or non-prescribed medication, menstrual cycle, sleeping pattern, drinking water, or other related behaviors.

To measure the duration, frequency, and intensity of pain, the study measures were administered at the baseline, post-test, and a 12-month follow-up. Moreover, weekly telephone follow-ups were made to enquire about the participants' experiences of pain, use of prescribed or non-prescribed medication, menstrual cycle, sleeping pattern, drinking water, or other related behaviors. The telephone calls also helped minimize the participants' dropouts. Participants were also reassured that they could have control visits during the study in case of experiencing migraine attacks or complications that could affect the intake of regular prescribed or non-prescribed medication. However, none of the participants in the experimental groups reported referring to their physician or resuming the use of migraine prescribed or non-prescribed medication at any of phone calls or follow-up assessments. Therefore, there was no data on prescribed or non-prescribed medication relapse for the experimental groups. The same experimenters administered all study measures at the baseline, post-test, and the follow-up assessments.

\section{Measures}

\section{Headache diary}

The Headache diary was used $(68,69)$ to record the frequency, (i.e., one attack per four weeks, one attack in two weeks, two or three attacks per week, or more than three attacks per week), duration (i.e., 4, 4-24, or 24-72 hours per attack), and the intensity of pain (i.e., moderate (1-3), severe (4-7), and worse possible case (8-10)) per migraine attack during the past four weeks. The measure has desirable reliability and validity indices $(68,69)$.

\section{Compliance with intervention}

Based on recorded data and the present study protocols, which included 36 sessions of jogging and 72 sessions of eye movement exercises or 72 sessions of diaphragmatic breathing for each study group, compliance with the intervention was assessed as follows: $36 / 36 \times 100=\%$ compliance or $72 / 72 \times 100=$ $\%$ compliance for each study group (70). During 36 sessions of jogging and 72 sessions of eye 
movement exercises or diaphragmatic breathing, each group of participants could skip sessions for a maximum of three (with a minimum compliance of $91.6 \%$ ) or six (with a minimum compliance of $95.8 \%$ ) sessions. Because there were no reports beyond the minimum compliance with interventions, further reports of the factor deemed unnecessary in the present study.

\section{Menstrual cycle, OTC, sleep, changes of drinking water, and exercise intolerance behaviors}

Prior to the study, an experimenter recorded information on (a) menstrual cycle; (b) over the counter (OTC) drug use; (c) sleep regimens (sleep and wake-up patterns), sleeping hours, and wake-up mode (71); (d) drinking water; and (e) exercise intolerance from the participants (Table 3). Menstrual cycle involved presence or absence of any effects on headache characteristics prior to, during, or after a menstrual period. Sleeping pattern involved going to sleep on time (between 9:00 p.m. and 11:00 p.m.) or late at night (after 11:30 p.m.). Sleeping hours included sleeping less than or more than seven hours per night (between 10:00 p.m. and 7:00 a.m.) (72, 73). In addition, drinking water was also recorded for the participants (74). However, any incidents of muscle cramps, fatigue, chronic dizziness, and vomiting, which were related to exercise intolerance were recorded. The data was recorded every other day during the experiment and every week during the 12-month follow-up. The rationale for recording and analyzing this data was to test whether the interventions influenced such variables beside migraine pain characteristics (Table 3).

\section{Data analysis}

To test the relative effect of jogging plus eye movement exercises or jogging plus diaphragmatic breathing, three multivariate analyses of covariance (MANCOVA) were conducted. To ensure that there were no missing data, initial data evaluation was performed for experimental and control groups. Next, assumptions of homogeneity, linearity, and normality of variance-covariance matrices were calculated and a $p$-value $\geq .05$ was set for all analyses. The results of models' fitness tests did not reveal any violation of underlying assumptions. In each model, group (three levels) was entered into the model as factor, pain characteristics (i.e., frequency, duration, and intensity of pain) at baseline were entered as covariates, and pain characteristics at the post-test and follow-up were entered into the model as dependent variables. Moreover, as secondary analyses, Cochran's tests were calculated to measure the effects of the two types of interventions on menstrual cycle, OTC, sleep, and drinking water as behavioral outcomes from baseline to post-test and the 12-month follow-up.

\section{Results}

Table 2 shows means and SDs of frequency, duration, and intensity of pain in each study group at baseline, post-test, and the 12-month follow-up assessments. 
Table 2

Mean and SDs for frequency, duration, and intensity of migraine pain in each study group across three assessment points.

\begin{tabular}{|c|c|c|c|c|c|c|c|c|c|}
\hline \multirow{2}{*}{$\begin{array}{l}\text { Groups; } \\
\text { Mean (SD) }\end{array}$} & \multicolumn{3}{|c|}{ Frequency } & \multicolumn{3}{|c|}{ Duration } & \multicolumn{3}{|c|}{ Intensity } \\
\hline & $\begin{array}{l}\text { Pre- } \\
\text { test }\end{array}$ & $\begin{array}{l}\text { Post- } \\
\text { test }\end{array}$ & $\begin{array}{l}\text { Follow- } \\
\text { up }\end{array}$ & $\begin{array}{l}\text { Pre- } \\
\text { test }\end{array}$ & $\begin{array}{l}\text { Post- } \\
\text { test }\end{array}$ & $\begin{array}{l}\text { Follow- } \\
\text { up }\end{array}$ & $\begin{array}{l}\text { Pre- } \\
\text { test }\end{array}$ & $\begin{array}{l}\text { Post- } \\
\text { test }\end{array}$ & $\begin{array}{l}\text { Follow- } \\
\text { up }\end{array}$ \\
\hline EM & $\begin{array}{l}9.15 \\
(2.68)\end{array}$ & $\begin{array}{l}2.40 \\
(1.46)\end{array}$ & $\begin{array}{l}2.70 \\
(1.21)\end{array}$ & $\begin{array}{l}8.10 \\
(3.29)\end{array}$ & $\begin{array}{l}1.80 \\
(1.36)\end{array}$ & $\begin{array}{l}1.95 \\
(0.99)\end{array}$ & $\begin{array}{l}6.50 \\
(1.67)\end{array}$ & $\begin{array}{l}1.20 \\
(0.83)\end{array}$ & $\begin{array}{l}2.20 \\
(0.95)\end{array}$ \\
\hline DB & $\begin{array}{l}8.22 \\
(4.00)\end{array}$ & $\begin{array}{l}1.61 \\
(1.24)\end{array}$ & $\begin{array}{l}1.44 \\
(1.79)\end{array}$ & $\begin{array}{l}6.50 \\
(2.77)\end{array}$ & $\begin{array}{l}0.89 \\
(0.67)\end{array}$ & $\begin{array}{l}1.11 \\
(1.41)\end{array}$ & $\begin{array}{l}6.11 \\
(1.32)\end{array}$ & $\begin{array}{l}0.94 \\
(0.72)\end{array}$ & $\begin{array}{l}1.50 \\
(1.29)\end{array}$ \\
\hline Control & $\begin{array}{l}8.80 \\
(2.48)\end{array}$ & $\begin{array}{l}8.33 \\
(2.66)\end{array}$ & $\begin{array}{l}9.20 \\
(4.34)\end{array}$ & $\begin{array}{l}8.07 \\
(3.97)\end{array}$ & $\begin{array}{l}8.00 \\
(3.87)\end{array}$ & $\begin{array}{l}7.80 \\
(3.07)\end{array}$ & $\begin{array}{l}7.07 \\
(1.79)\end{array}$ & $\begin{array}{l}6.80 \\
(1.56)\end{array}$ & $\begin{array}{l}6.20 \\
(1.29)\end{array}$ \\
\hline
\end{tabular}

\section{Primary data analyses}

In each MANCOVA model, group showed a significant multivariate effect on the frequency (Wilk's =.20; $F$ $(4,96)=28.93 ; p=.001 ; \eta 2$ (Cohen's $\mathrm{d})=.54(2.16))$, duration $\left(\right.$ Wilk's $=.16 ; F_{(4,96)}=34.34 ; p=.001 ; \eta 2$ $($ Cohen's $\mathrm{d})=.58(2.35))$, and intensity $\left(\right.$ Wilk's $=.09 ; F_{(4,96)}=53.14 ; p=.001 ; \eta 2($ Cohen's $\left.\mathrm{d})=.68(2.91)\right)$ of the pain at the post-test and follow-up assessments. Pairwise comparisons showed that, compared to the control group, the experimental groups showed significant improvements in all pain characteristics at the post-test and follow-up assessments (Table 3). There was no significant difference between the two experimental groups on any of the pain characteristics. The effect sizes for all models were greater than Cohen's $d=.80$ for a large effect size (Table 3 ). Figure 4 shows changes in the migraine pain across assessment points for each group. 
Table 3

Results of three MANCOVA models testing inter-group effects at post-test and a 12-month follow-up.

\begin{tabular}{|c|c|c|c|c|c|c|c|}
\hline & \multicolumn{6}{|c|}{ Main effects } & \multirow{2}{*}{$\begin{array}{l}\text { Pairwise } \\
\text { comparisons } \\
(p<001)\end{array}$} \\
\hline DVs & & Assessment & $\begin{array}{l}\text { Wilks' } \lambda \\
(4,96)\end{array}$ & $\begin{array}{l}F(4, \\
96)\end{array}$ & $p$ & $\begin{array}{l}\eta^{2} \\
\text { (Cohen's } \\
\text { d) }\end{array}$ & \\
\hline \multirow[t]{6}{*}{$\begin{array}{l}\text { Migraine } \\
\text { attacks }\end{array}$} & \multirow[t]{2}{*}{ Frequency } & Post-test & 0.20 & 78.59 & .001 & $\begin{array}{l}.79 \\
(3.55)\end{array}$ & ME\&DB $<$ Ctrl \\
\hline & & Follow-up & & 50.93 & .001 & $\begin{array}{l}.67 \\
(2.84)\end{array}$ & ME\&DB $<$ Ctrl \\
\hline & \multirow[t]{2}{*}{ Duration } & Post-test & 0.16 & 89.28 & .001 & $\begin{array}{l}.78 \\
(3.76)\end{array}$ & ME\&DB $<$ Ctrl \\
\hline & & Follow-up & & 77.40 & .001 & $\begin{array}{l}.76 \\
(3.55)\end{array}$ & ME\&DB $<$ Ctrl \\
\hline & \multirow[t]{2}{*}{ Intensity } & Post-test & 0.09 & 166.81 & .001 & $\begin{array}{l}.87 \\
(5.17)\end{array}$ & ME\&DB $<$ Ctrl \\
\hline & & Follow-up & & 69.53 & .001 & $\begin{array}{l}.73 \\
(3.28)\end{array}$ & ME\&DB < Ctrl \\
\hline
\end{tabular}

\section{Secondary data analysis}

The results of a series of Cochran's tests were used to test changes in the patients' menstrual cycle, OTC, sleep pattern, and drinking water across the assessment points and showed significant improvements for the experimental groups but not for the control group (Table 4). None of the participants in the experimental groups complained of adverse effects like muscle cramps, fatigue, chronic dizziness, or vomiting on exertion or after exercise. 
Table 4

Results of Cochran's Q models testing inter-group effects at post-test and a 12-month follow-up.

\begin{tabular}{|c|c|c|c|c|c|c|c|}
\hline \multirow[b]{2}{*}{ Variables } & \multirow[b]{2}{*}{ Factors } & \multirow[b]{2}{*}{ Groups } & \multicolumn{3}{|c|}{ Frequency } & \multirow[b]{2}{*}{$\begin{array}{l}\text { Cochran's } \\
Q\end{array}$} & \multirow[b]{2}{*}{$P$} \\
\hline & & & $\begin{array}{l}\text { Pre- } \\
\text { test }\end{array}$ & $\begin{array}{l}\text { Post- } \\
\text { test }\end{array}$ & $\begin{array}{l}\text { Follow- } \\
\text { up }\end{array}$ & & \\
\hline \multirow{3}{*}{$\begin{array}{l}\text { Menstrual } \\
\text { Cycle }\end{array}$} & \multirow[t]{3}{*}{ No Effect: Increase } & EM & $13: 5$ & $18: 0$ & $18: 0$ & 10.00 & .007 \\
\hline & & DB & $15: 5$ & $20: 0$ & $20: 0$ & 10.00 & .007 \\
\hline & & Control & $10: 5$ & $11: 4$ & $14: 1$ & 6.50 & .03 \\
\hline \multirow{3}{*}{$\begin{array}{l}\text { Over the } \\
\text { Counter }\end{array}$} & \multirow[t]{3}{*}{ No Use: Use } & EM & $0: 18$ & $2: 16$ & $4: 14$ & 4.80 & .09 \\
\hline & & DB & $0: 20$ & $7: 13$ & $4: 16$ & 9.25 & .01 \\
\hline & & Control & $2: 13$ & $1: 14$ & $1: 14$ & .66 & .71 \\
\hline \multirow[t]{3}{*}{ Wake_up_Mode } & \multirow{3}{*}{$\begin{array}{l}\text { Refreshed : Sleepy or } \\
\text { Tired }\end{array}$} & EM & $5: 13$ & $18: 0$ & $18: 0$ & 26.00 & .001 \\
\hline & & DB & $0: 20$ & $19: 1$ & $18: 2$ & 34.30 & .001 \\
\hline & & Control & $3: 12$ & $1: 14$ & $0: 15$ & 4.66 & .09 \\
\hline \multirow[t]{3}{*}{ Sleep Hours } & \multirow{3}{*}{$\begin{array}{l}\text { Less than Seven } \\
\text { Hours: } \\
\text { More than Seven } \\
\text { Hours }\end{array}$} & EM & $16: 2$ & $9: 9$ & $12: 6$ & 5.69 & .05 \\
\hline & & DB & $18: 2$ & $14: 6$ & $12: 8$ & 4.30 & .11 \\
\hline & & Control & $13: 2$ & $13: 2$ & $13: 2$ & 0.00 & 1.00 \\
\hline \multirow{3}{*}{$\begin{array}{l}\text { Sleeping } \\
\text { Pattern }\end{array}$} & \multirow[t]{3}{*}{ On time : Late } & EM & $4: 14$ & $12: 6$ & $15: 3$ & 14.92 & .001 \\
\hline & & DB & $3: 17$ & $14: 6$ & $13: 7$ & 13.87 & .001 \\
\hline & & Control & $2: 13$ & $1: 14$ & $1: 14$ & 0.66 & .71 \\
\hline \multirow[t]{3}{*}{ Drinking water } & \multirow[t]{3}{*}{ No: Yes } & EM & $14: 4$ & $1: 17$ & $0: 18$ & 24.40 & .001 \\
\hline & & DB & $19: 1$ & $3: 17$ & $6: 14$ & 24.11 & .001 \\
\hline & & Control & $14: 1$ & $13: 2$ & $13: 2$ & .66 & .717 \\
\hline
\end{tabular}

Given the loss of participants from post-test to the follow-up (see Flowchart), we did not have full compliance with the present study intervention protocols; the compliance rates were: $53 / 63 \times 100=84.1 \%$ compliance for the total sample; $20 / 22 \times 100=90.9 \%$ compliance for the jogging plus eye movement exercises group; $18 / 19 \times 100=94.7 \%$ compliance for the jogging plus diaphragmatic breathing; and $15 / 22 \times 100=61.1 \%$ compliance for the control group.

\section{Discussion}


The present study tested the effectiveness of jogging, eye movement exercises, and diaphragmatic breathing in patients with migraine pain. The first experimental group received jogging plus eye movement exercises and the second experimental group received jogging plus diaphragmatic breathing, whereas the control group only received treatment as usual. The results showed significant effects of the interventions on the patients' symptoms in the experimental groups (Fig. 4 and Table 3). Therefore, regular aerobic exercises (i.e., jogging) and practicing body-mind awareness (i.e., eye movement exercises and diaphragmatic breathing) appear to elucidate the negative effects of stressful insults in the brain, on the body muscles, respiratory rate and depth, and the flow of biomolecules and hormones (i.e., Nitric Oxide (NO), brain-derived neurotrophic factor (BDNF), and adenosine monophosphate-activated protein kinase (AMPK)). These effects could stem from various possible mechanisms, including (a) brain-gut and neuroimmune axis (e.g., hypothalamus-pituitary-adrenal (HPA); (b) brain-brain reciprocal interlinks (e.g., hippocampus-anterior cingulate cortex and medial-prefrontal cortex (mPFC) oscillations); and (c) circadian disruption and biomolecular dysregulation (e.g., oxidative stress and neurogenic inflammation), each of which may play a key initiating role in spurring migraine-related symptoms (75-78).

Although the results of a meta-analysis (29) suggested that the effect of aerobic exercise on patients with migraine is only related to the frequency of the attacks, in a recent study (79), aerobic exercises are assumed to influence all aspects of migraine pain including frequency, duration, and intensity. The paradoxical findings in the literature on the effectiveness of aerobic exercise could be related to the following reasons. First, based on the International Headache Society $(\mathrm{IHS})$ recommendations $(69,80)$, one major drawback of previous studies is heterogeneity in applying headache-related outcome measures. Second, some studies have failed to adequately address issues related to blinding, sample size, designing, and randomization. Third, no study has compared the outcomes of aerobic exercises on patients with migraine without aura (MwoA) and patients with migraine with aura (MwA). Forth, evidence was scarce for comparing the outcomes of aerobic exercises and pharmacological treatment of migraine pain. Fifth, in no study so far aerobic exercise has been complemented with another non-medication intervention; therefore, this was the first study that, based on findings from the migraine brain studies, combined jogging with eye movement exercises or diaphragmatic breathing to decrease kinesiophobia or sensitivity to movements in migraine patients $(81,82)$.

As a diagnostic criterion, patients with migraine have a fear of movement or kinesiophobia (83-85). To develop readiness for and potentiate neural responsiveness to a full-body exercise and to improve body awareness $(65,66)$, the present study provided the patients with eye movement exercises or diaphragmatic breathing (86-88). Considering the neural or Hebbian learning, stimulating brain on a regular basis adjusts brain functions at the molecular level (e.g., signaling mechanisms and memory formation) (89). Eye movement exercises are identified to activate widespread, interconnected cortical and subcortical networks such as superior colliculus, oculomotor network (ON) in the brain stem, dorsolateral prefrontal brain cortex, basal ganglia, subthalamic structures, substantia nigra pars reticulata, visuo-motor, parietal, and posterior cingulate cortices (90-94). Each of these networks plays an excitatory or inhibitory role in pain processing $(95,96)$. Therefore, performing eye movement exercises on a regular basis stimulates or potentiates almost all major parts of the brain that are important in the 
experience of the pain. The corneoretinal potential (CRP) transduction by eye movement exercises is a bioelectrical signal, which is produced by two modes of polarities during eye movement exercises: a positively charged end (cornea) and a negatively charged end (retina) (97). The conjugated eye movement exercises (i.e., from right to left or from top to bottom and the vice versa) transduces sequential negative or positive electrical charges on the retina (98). These types of training-induced transduction should potentiate synaptic plasticity and facilitate myelination mechanisms by (a) regulating signal transmission (i.e., neuromodulation of ion channels and neurotransmitters); (b) synchronizing oscillations (i.e., frequency, amplitude, or phase); and (c) cortical reorganization or enhancement of timing within related cortical-cortical or cortical-subcortical brain networks (i.e., enhancement of memory, visuospatial accuracy, decision-making, or task switching) (99-103).

In the present study, another essential guided behavior was diaphragmatic breathing. In the present study, another essential guided behavior was diaphragmatic breathing. It should be noted that jogging itself may increase exercise-induced stress insults in migraine brain; however, diaphragmatic breathing helps with promoting stress-response control indices and potentiating cortical readiness prior to jogging $(104,105)$. Diaphragmatic breathing can improve brain function via the following mechanisms: (a) chemical, which involves the regulation of biomolecules such as adenosine, melatonin, orexin, or calcitonin-gene-related peptide (CGRP); (b) mechanical, which involves enhancing the rate, length, or intensity of breathing at the cortical level; and (c) cortical-subcortical control, which is related to shared breathing centers and headache-related networks such as brainstem and medullary centers (106109). Together, jogging, eye movement exercises, and diaphragmatic breathing may induce mitochondrial oxidative phosphorylation, electrical transduction, ionic, and biomolecule homeostasis that can explain primary and secondary outcomes of the present study.

All participants in the present study were female patients with episodic migraine. This may limit the generalizability of our findings to male patients with migraine. Subsequently, the same study should be also conducted with male migraine patients. Moreover, heterogeneity in the rate of prescribed and OTC medication use in the control group was another limitation of the present study. Moreover, we did not ask patients in the control group to keep a journal of any medication that they were taking for their pain because, there is no single or specific medication with consistent or long-term effect for migraine, hence even recording the rate of medication use over a two-year by the patients in the control group deemed an unviable goal and could not help with interpreting the study outcomes. Furthermore, given that the present study was conducted in a Middle Eastern country with a different environment and culture, future studies can replicate the study with patients from different cultural, racial, and ethnical backgrounds. Future studies can also examine the outcomes of the present interventions for other types of headache, migraine-related comorbidities (e.g., epilepsy, tinnitus, chronic dizziness or vertigo, sleep apnea, or restless leg syndrome), and even for psychopathologies like depression and anxiety.

\section{Conclusion}


The primary outcomes of the present study can be summarized as positive effects of jogging plus eye movement exercises or jogging plus diaphragmatic breathing on decreasing the frequency, duration, and intensity of pain in patients with migraine. The secondary outcomes could be summarized as decreased headache attacks associated with menstrual cycle and use of OTC medication, and on improving sleep and drinking water. Together, interventions used the present study offer promising prophylactic and therapeutic outcomes for patients with migraine.

\section{Clinical implications}

Performing 12-week jogging (every other day $\approx 25$-min) either with eye movement exercises (60 rounds early in the morning / 60 rounds before the bedtime) or diaphragmatic breathing ( 3 times a day, each time for $\approx 5$-min)

- can significantly reduce the measured aspects of episodic migraine pain characteristics.

- offers a safe and convenient intervention.

- produces no short-term or long-term undesirable side effects.

\section{Abbreviations}

ED

electrophysiological dysresponsiveness

NO

Nitric Oxide

BDNF

Brain-Derived Neurotrophic Factor

ICHD-3

International Classification of Headache Disorders 3rd edition

TAU

Treatment as usual

CBF

Cerebral blood flow

$\mathrm{MOH}$

Medication overuse headache

NMDA

N-Methyl-D-Aspartate

PHA

Hypothalamus-pituitary-adrenal

MwA

Migraine with aura

MwoA

Migraine without aura 
OTC

Over the counter drugs

CRP

corneoretinal potential

EM

Eye movement

DB

Diaphragmatic breathing

\section{Declarations}

\section{Availability of data and material}

All data generated or analyzed during the present study are included in this manuscript and its supplementary information files will be available on demand.

\section{Ethics declarations}

\section{Ethics approval}

The study was approved by the ethics committee of Mashhad University of Medical Sciences (Ir.mums.fm.rec.1396.362).

\section{Consent for publication}

All subjects provided written informed consent for publication prior to the present study enrolment.

\section{Competing interests}

The authors declare that they have no competing interests.

\section{Acknowledgement}

We thank our colleagues who commented on an earlier version of the present article, the anonymous reviewers whose comments assisted with the quality of the article, and patients who participated in our study. The authors have no conflict of interest to declare.

Funding: It should be acknowledged that the present study did not receive any full or partial financial support.

\section{Authors' contributions}


Mohammad Dawood Rahimi: Conceptualization, Methodology, Data curation, Investigation, Project administration, Writing-original draft. Fatemeh Alidoosti: Formal analysis. Pouriya Hassani: Investigation. Mohammad Mahdi Ghasemi: Resources, Supervision. Javad Salehi Fadardi: Supervision, Reviewing \& Editing

\section{References}

1. Kucyi A, Davis KD (2015) The dynamic pain connectome. Trends in neurosciences 38(2):86-95

2. Espinosa-Sanchez JM, Lopez-Escamez JA (2015) New insights into pathophysiology of vestibular migraine. Front Neurol 6:12

3. Rahimi MD, Fadardi JS, Saeidi M, Bigdeli I, Kashiri R (2020) Effectiveness of cathodal tDCS of the primary motor or sensory cortex in migraine: A randomized controlled trial. Brain Stimulation 13(3):675-682

4. Li K, Liu L, Yin Q, Dun W, Xu X, Liu J et al (2017) Abnormal rich club organization and impaired correlation between structural and functional connectivity in migraine sufferers. Brain Imaging Behav 11(2):526-540

5. DeBuc DC, Somfai GM, Szatmáry G, Arthur E, Jimenez JA, Mendoza-Santiesteban C et al. Seeing the Brain Through the Eye: What Is Next for Neuroimaging and Neurology Applications. OCT and Imaging in Central Nervous System Diseases: Springer; 2020. p. 55-82

6. Polak K, Luksch A, Frank B, Jandrasits K, Polska E, Schmetterer L (2003) Regulation of human retinal blood flow by endothelin-1. Exp Eye Res 76(5):633-640

7. Zhang C, Hein TW, Wang W, Chang C-I, Kuo L (2001) Constitutive expression of arginase in microvascular endothelial cells counteracts nitric oxide-mediated vasodilatory function. FASEB J 15(7):1264-1266

8. Lee S-T, Chu K, Jung K-H, Kim D-H, Kim E-H, Choe V et al (2008) Decreased number and function of endothelial progenitor cells in patients with migraine. Neurology 70(17):1510-1517

9. Tang X, Luo Y-X, Chen H-Z, Liu D-P (2014) Mitochondria, endothelial cell function, and vascular diseases. Frontiers in physiology 5:175

10. Dreier JP, Reiffurth C (2015) The stroke-migraine depolarization continuum. Neuron 86(4):902-922

11. Picón-Pagès P, Garcia-Buendia J, Muñoz FJ. Functions and dysfunctions of nitric oxide in brain. Biochimica et Biophysica Acta (BBA)-Molecular Basis of Disease. 2019;1865(8):1949-67

12. Chen O, Donnelly CR, Ji RR (2019) Regulation of pain by neuro-immune interactions between macrophages and nociceptor sensory neurons. Curr Opin Neurobiol 62:17-25

13. Merighi A, Salio C, Ghirri A, Lossi L, Ferrini F, Betelli C et al (2008) BDNF as a pain modulator. Prog Neurobiol 85(3):297-317

14. De Vincenti AP, Ríos AS, Paratcha G, Ledda F (2019) Mechanisms That Modulate and Diversify BDNF Functions: Implications for Hippocampal Synaptic Plasticity. Front Cell Neurosci 13:135 
15. Zamanian-Azodi M, Rezaei-Tavirani M, Robati RM (2019) Introducing Genes With Significant Role in Migraine: An Interactomic Approach. Basic Clinical Neuroscience 10(4):363-372

16. Guo J-Q, Deng H-H, Bo X, Yang X-S (2017) Involvement of BDNF/TrkB and ERK/CREB axes in nitroglycerin-induced rat migraine and effects of estrogen on these signals in the migraine. Biology open 6(1):8-16

17. Khosravi A, Nakhaee A, Ghoreishi A, Arefpoor Z, Sadeghi M (2019) Impaired oxidative-antioxidative balance during migraine attack. Biomedical Research Therapy 6(2):2996-3002

18. González-Rodríguez P, Ugidos IF, Pérez-Rodríguez D, Anuncibay-Soto B, Santos-Galdiano M, FontBelmonte $\mathrm{E}$ et al (2019) Brain-derived neurotrophic factor alleviates the oxidative stress induced by oxygen and glucose deprivation in an ex vivo brain slice model. Journal of cellular physiology 234(6):9592-9604

19. Campillos M, Kuhn M, Gavin A-C, Jensen LJ, Bork P (2008) Drug target identification using sideeffect similarity. Science 321(5886):263-266

20. Calabresi P, Cupini L (2005) Medication-overuse headache: pathophysiological insights. J Headache Pain 6(4):199-202

21. Tepper SJ (2012) Medication-overuse headache. Continuum (Minneap Minn) 18(4):807-822

22. Binder DK, Croll SD, Gall CM, Scharfman HE (2001) BDNF and epilepsy: too much of a good thing? Trends in neurosciences 24(1):47-53

23. Obata K, Noguchi K (2006) BDNF in sensory neurons and chronic pain. Neurosci Res 55(1):1-10

24. Xu H, Richardson JS, Li X-M (2003) Dose-related effects of chronic antidepressants on neuroprotective proteins $\mathrm{BDNF}, \mathrm{Bcl}-2$ and $\mathrm{Cu} / \mathrm{Zn}-\mathrm{SOD}$ in rat hippocampus. Neuropsychopharmacology 28(1):53

25. Burgos-Vega CC, Quigley LD, Avona A, Price T, Dussor G (2016) Dural stimulation in rats causes BDNF-dependent priming to subthreshold stimuli including a migraine trigger. Pain 157(12):2722

26. Fidan I, Yüksel S, Ýmir T, İrkeç C, Aksakal FN (2006) The importance of cytokines, chemokines and nitric oxide in pathophysiology of migraine. J Neuroimmunol 171(1):184-188

27. STARLING AJ (2019) SEEDS for success: Lifestyle management in migraine. Cleve Clin J Med 86(11):741

28. Lemmens J, De Pauw J, Van Soom T, Michiels S, Versijpt J, van Breda E et al (2019) The effect of aerobic exercise on the number of migraine days, duration and pain intensity in migraine: a systematic literature review and meta-analysis. J Headache Pain 20(1):16

29. Naugle KM, Fillingim RB, Riley JL III (2012) A meta-analytic review of the hypoalgesic effects of exercise. The Journal of pain 13(12):1139-1150

30. Lima LV, Abner TS, Sluka KA (2017) Does exercise increase or decrease pain? Central mechanisms underlying these two phenomena. J Physiol 595(13):4141-4150

31. Andreou AP, Goadsby PJ (2009) Therapeutic potential of novel glutamate receptor antagonists in migraine. Expert opinion on investigational drugs 18(6):789-803 
32. Wang DD, Kriegstein AR (2008) GABA regulates excitatory synapse formation in the neocortex via NMDA receptor activation. J Neurosci 28(21):5547-5558

33. Manzoni O, Prezeau L, Marin P, Desagher S, Deshager S, Bockaert J et al (1992) Nitric oxide-induced blockade of NMDA receptors. Neuron 8(4):653-662

34. Ye ZC, Sontheimer H (1996) Cytokine modulation of glial glutamate uptake: a possible involvement of nitric oxide. Neuroreport 7(13):2181-2185

35. Ramadan NM (2003) The link between glutamate and migraine. CNS Spectr 8(6):446-449

36. Cotman CW, Berchtold NC (2002) Exercise: a behavioral intervention to enhance brain health and plasticity. Trends Neurosci 25(6):295-301

37. Xu B (2013) BDNF (I)rising from Exercise. Cell Metab 18(5):612-614

38. Almeida R, Manadas B, Melo C, Gomes J, Mendes C, Graos M et al (2005) Neuroprotection by BDNF against glutamate-induced apoptotic cell death is mediated by ERK and PI3-kinase pathways. Cell death differentiation 12(10):1329

39. Martínez F, Castillo J, Rodríguez JR, Leira R, Noya M (1993) Neuroexcitatory amino acid levels in plasma and cerebrospinal fluid during migraine attacks. Cephalalgia 13(2):89-93

40. Marosi K, Mattson MP (2014) BDNF mediates adaptive brain and body responses to energetic challenges. Trends Endocrinol Metab 25(2):89-98

41. Van Mil AH, Spilt A, Van Buchem MA, Bollen EL, Teppema L, Westendorp RG et al (2002) Nitric oxide mediates hypoxia-induced cerebral vasodilation in humans. J Appl Physiol 92(3):962-966

42. Dinç ME, Muluk NB, Vonakis BM (2020) Physiology of the Nose and Paranasal Sinuses. Springer, All Around the Nose, pp 57-63

43. Ellegård EK (2006) Pregnancy rhinitis. Immunol Allergy Clin North Am 26(1):119-135, vii

44. Sparks DL (2002) The brainstem control of saccadic eye movements. Nat Rev Neurosci 3(12):952964

45. Dorner GT, Garhofer G, Kiss B, Polska E, Polak K, Riva CE et al (2003) Nitric oxide regulates retinal vascular tone in humans. Am J Physiol Heart Circ Physiol 285(2):H631-H636

46. Savchenko A, Barnes S, Kramer RH (1997) Cyclic-nucleotide-gated channels mediate synaptic feedback by nitric oxide. Nature 390(6661):694-698

47. Matteo BM, Viganò B, Cerri CG, Perin C (2016) Visual field restorative rehabilitation after brain injury. J Vis 16(9):11-

48. Ploughman M, Granter-Button S, Chernenko G, Attwood Z, Tucker BA, Mearow KM et al (2007) Exercise intensity influences the temporal profile of growth factors involved in neuronal plasticity following focal ischemia. Brain Res 1150:207-216

49. Tutakhail A, Boulet L, Khabil S, Nazari QA, Hamid H, Coudoré F. Neuropathology of Kynurenine Pathway of Tryptophan Metabolism. Current Pharmacology Reports.1-16

50. Mahgoub MO, D'Souza C, Al Darmaki RSMH, Baniyas MMYH, Adeghate E (2018) An update on the role of irisin in the regulation of endocrine and metabolic functions. Peptides 104:15-23 
51. Bereiter-Hahn J, Jendrach M. Environmental Stress: Mitochondria as Targets and Stressors in Cellular Metabolism. Stress Challenges and Immunity in Space: Springer; 2020. p. 43-70

52. Gross NB, Abad N, Lichtstein D, Taron S, Aparicio L, Fonteh AN et al. Endogenous Na+, K+-ATPase inhibitors and CSF [Na+] contribute to migraine formation. PloS one. 2019;14(6)

53. Rehman J, Li J, Parvathaneni L, Karlsson G, Panchal VR, Temm CJ et al (2004) Exercise acutely increases circulating endothelial progenitor cells and monocyte/macrophage-derived angiogenic cells. J Am Coll Cardiol 43(12):2314-2318

54. Narin SO, Pinar L, Erbas D, Oztürk V, Idiman F (2003) The effects of exercise and exercise-related changes in blood nitric oxide level on migraine headache. Clinical rehabilitation 17(6):624-630

55. Oldfield RC (1971) The assessment and analysis of handedness: the Edinburgh inventory. Neuropsychologia 9(1):97-113

56. van den Brink AM, MacGregor EA. Gender and Migraine: Springer; 2019

57. Labastida-Ramírez A, Rubio-Beltrán E, Villalon CM, MaassenVanDenBrink A (2019) Gender aspects of CGRP in migraine. Cephalalgia 39(3):435-444

58. Kurth T, Slomke M, Kase C, Cook N, Lee I-M, Gaziano J et al (2005) Migraine, headache, and the risk of stroke in women: a prospective study. Neurology 64(6):1020-1026

59. (IHS) HCCotlHS. The International Classification of Headache Disorders, 3rd edition (beta version). Cephalalgia. 2013;33(9):629-808

60. Ferrari A, Baraldi C, Sternieri E (2015) Medication overuse and chronic migraine: a critical review according to clinical pharmacology. Expert Opin Drug Metab Toxicol 11(7):1127-1144

61. Lachin JM (1988) Properties of simple randomization in clinical trials. Control Clin Trials 9(4):312326

62. Jain S (2019) Applied Physiology of Eye Movements. In: Jain S (ed) Simplifying Strabismus: A Practical Approach to Diagnosis and Management. Springer International Publishing, Cham, pp 1522

63. Leigh RJ, Zee DS. The neurology of eye movements: OUP USA; 2015

64. Lampl C, Rudolph M, Deligianni Cl, Mitsikostas DD (2015) Neck pain in episodic migraine: premonitory symptom or part of the attack? J Headache Pain 16(1):80

65. Guyenet Patrice G, Bayliss Douglas A (2015) Neural Control of Breathing and CO2 Homeostasis. Neuron 87(5):946-961

66. Adler D, Herbelin B, Similowski T, Blanke O (2014) Reprint of "Breathing and sense of self: Visuorespiratory conflicts alter body self-consciousness". Respir Physiol Neurobiol 204:131-137

67. Jo S-H (2019) How to Sit in Sitting Meditation. Mindfulness 10(11):2468-2471

68. Niere K, Jerak A (2004) Measurement of headache frequency, intensity and duration: comparison of patient report by questionnaire and headache diary. Physiotherapy research international 9(4):149156 
69. Tassorelli C, Diener H-C, Dodick DW, Silberstein SD, Lipton RB, Ashina M et al (2018) Guidelines of the International Headache Society for controlled trials of preventive treatment of chronic migraine in adults. Cephalalgia 38(5):815-832

70. van der Horst N, Smits D-W, Petersen J, Goedhart EA, Backx FJ (2015) The preventive effect of the nordic hamstring exercise on hamstring injuries in amateur soccer players: a randomized controlled trial. Am J Sports Med 43(6):1316-1323

71. Panda S. The Circadian Code: Lose Weight, Supercharge Your Energy, and Transform Your Health from Morning to Midnight: Rodale Books; 2020

72. Bertisch S, Li W, Buettner C, Mostofsky E, Rueschman M, Burstein R et al (2018) 1017 Sleep Duration, Fragmentation, And Quality And Risk Of Next-day Migraine. Sleep 41:A377

73. Finan PH, Goodin BR, Smith MT (2013) The association of sleep and pain: an update and a path forward. J Pain 14(12):1539-1552

74. Barraj L, Scrafford C, Lantz J, Daniels C, Mihlan G (2009) Within-day drinking water consumption patterns: results from a drinking water consumption survey. J Expo Sci Environ Epidemiol 19(4):382-395

75. Ketchesin KD, Becker-Krail D, McClung CA (2020) Mood-related central and peripheral clocks. Eur J Neurosci 51(1):326-345

76. Karapanou V, Kempuraj D, Theoharides T (2009) Oral neuroimmune network and mast cells. SAGE Publications Sage UK, London

77. Fornari RV, Aerni A, Dominique J-F, Roozendaal B. Neurobiological Mechanisms of Stress and Glucocorticoid Effects on Learning and Memory: Implications for Stress Disorders on Earth and in Space. Stress Challenges and Immunity in Space: Springer; 2020. p. 95-122

78. Kempuraj D, Mentor S, Thangavel R, Ahmed ME, Selvakumar GP, Raikwar SP et al (2020) Mast Cells in Stress, Pain, Blood-Brain Barrier, Neuroinflammation and Alzheimer's. Mast Cells in Itch, Pain

79. La Touche R, Fernández Pérez JJ, Proy Acosta A, González Campodónico L, Martínez García S, Adraos Juárez $D$ et al. Is aerobic exercise helpful in patients with migraine? A systematic review and meta-analysis. Scandinavian Journal of Medicine \& Science in Sports. 2020

80. Silberstein S, Tfelt-Hansen P, Dodick DW, Limmroth V, Lipton RB, Pascual J et al (2008) Guidelines for controlled trials of prophylactic treatment of chronic migraine in adults. Cephalalgia 28(5):484-495

81. Goadsby PJ, Lipton RB, Ferrari MD (2002) Migraine-current understanding and treatment. New England journal of medicine 346(4):257-270

82. Rainero I, Roveta F, Vacca A, Noviello C, Rubino E. Migraine pathways and the identification of novel therapeutic targets. Expert Opinion on Therapeutic Targets. 2020:1-9

83. Benatto MT, Bevilaqua-Grossi D, Carvalho GF, Bragatto MM, Pinheiro CF, Straceri Lodovichi S et al (2019) Kinesiophobia is associated with migraine. Pain Med 20(4):846-851

84. Scholten-Peeters GG, Coppieters MW, Durge TS, Castien RF (2020) Fluctuations in local and widespread mechanical sensitivity throughout the migraine cycle: a prospective longitudinal study. 
The Journal of Headache Pain 21(1):1-11

85. Holmberg JM. Pathophysiology, Differential Diagnosis, and Management of Persistent PosturalPerceptual Dizziness: A Review. Perspectives of the ASHA Special Interest Groups. 2020:1-11

86. Schurger A, Sitt JD, Dehaene S. An accumulator model for spontaneous neural activity prior to selfinitiated movement. Proceedings of the National Academy of Sciences. 2012;109(42):E2904-E13

87. Murakami M, Vicente MI, Costa GM, Mainen ZF (2014) Neural antecedents of self-initiated actions in secondary motor cortex. Nature neuroscience 17(11):1574

88. Schurger A, Mylopoulos M, Rosenthal D (2016) Neural antecedents of spontaneous voluntary movement: a new perspective. Trends in Cognitive Sciences 20(2):77-79

89. Csermely P, Kunsic N, Mendik P, Kerestély M, Faragó T, Veres DV et al. Learning of signaling networks: molecular mechanisms. Trends in Biochemical Sciences. 2020

90. Bolam J, Hanley J, Booth P, Bevan M (2000) Synaptic organisation of the basal ganglia. The Journal of Anatomy 196(4):527-542

91. Santamaria L, Noreika V, Georgieva S, Clackson K, Wass S, Leong V (2020) Emotional valence modulates the topology of the parent-infant inter-brain network. Neurolmage 207:116341

92. Burke MJ, Joutsa J, Cohen AL, Soussand L, Cooke D, Burstein R et al. Mapping migraine to a common brain network. Brain. 2020

93. Srivastava A, Ahmad OF, Pacia CP, Hallett M, Lungu C (2018) The Relationship between Saccades and Locomotion. Journal of movement disorders 11(3):93

94. Rucker J (2010) Eye Movement Abnormalities in Movement Disorders. Encyclopedia of Movement Disorders 1:462

95. Coiner B, Pan H, Bennett ML, Bodien YG, lyer S, O'Neil-Pirozzi TM et al (2019) Functional neuroanatomy of the human eye movement network: a review and atlas. Brain Structure Function 224(8):2603-2617

96. Caulo M, Maruotti V, Ferretti A (2019) Brain Imaging of Pain. Springer, Pain Imaging, pp 7-22

97. Shepard NT, Schubert MC, Eggers SD. Eye Movement Recording and Ocular Motility Testing. Balance Function Assessment and Management. 2020:189

98. Klein C, Ettinger U. Eye Movement Research: An Introduction to Its Scientific Foundations and Applications: Springer Nature; 2019

99. Perrin P, Schneider D, Deviterne D, Perrot C, Constantinescu L (1998) Training improves the adaptation to changing visual conditions in maintaining human posture control in a test of sinusoidal oscillation of the support. Neurosci Lett 245(3):155-158

100. Slagter HA, Vissers ME, Talsma LJ, Ridderinkhof KR (2017) Cognitive enhancement: it's about time. Cognitive neuroscience 8(2):119-120

101. Hutton SB (2008) Cognitive control of saccadic eye movements. Brain cognition 68(3):327-340

102. Pierrot-Deseilligny C, Milea D, Müri RM (2004) Eye movement control by the cerebral cortex. Curr Opin Neurol 17(1):17-25 
103. Liu J, Zhao L, Lei F, Zhang Y, Yuan K, Gong Q et al (2015) Disrupted resting-state functional connectivity and its changing trend in migraine suffers. Hum Brain Mapp 36(5):1892-1907

104. Park H-D, Barnoud C, Trang H, Kannape OA, Schaller K, Blanke O (2020) Breathing is coupled with voluntary action and the cortical readiness potential. Nat Commun 11(1):1-8

105. Martarelli D, Cocchioni M, Scuri S, Pompei P. Diaphragmatic breathing reduces exercise-induced oxidative stress. Evidence-Based Complementary and Alternative Medicine. 2011;2011

106. Sclocco R, Garcia RG, Kettner NW, Isenburg K, Fisher HP, Hubbard CS et al (2019) The influence of respiration on brainstem and cardiovagal response to auricular vagus nerve stimulation: a multimodal ultrahigh-field (7T) fMRI study. Brain Stimul 12(4):911-921

107. Vila-Pueyo M, Hoffmann J, Romero-Reyes M, Akerman S. Brain structure and function related to headache: Brainstem structure and function in headache. Cephalalgia. 2018:333102418784698

108. Reiter RJ, Tan DX, Maldonado MD (2005) Melatonin as an antioxidant: physiology versus pharmacology. Journal of pineal research 39(2):215-216

109. Peña LO, Martínez MS, Carmona AF. Spontaneous Breathing Pattern. Ventilatory Support and Oxygen Therapy in Elder, Palliative and End-of-Life Care Patients: Springer; 2020. p. 3-13

\section{Figures}




\section{Enrollment}

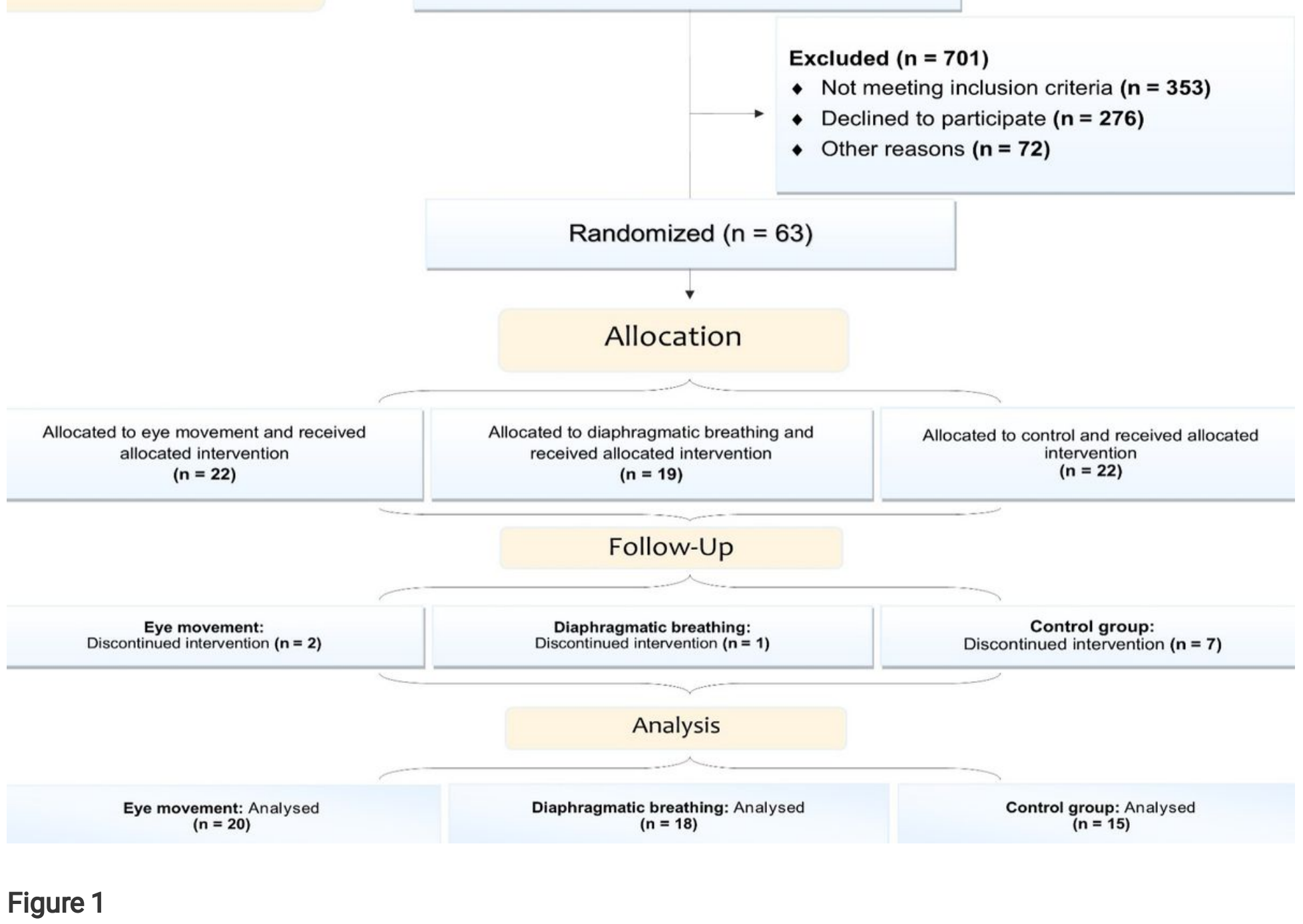

Flow of study population from 2016 to 2019 . 


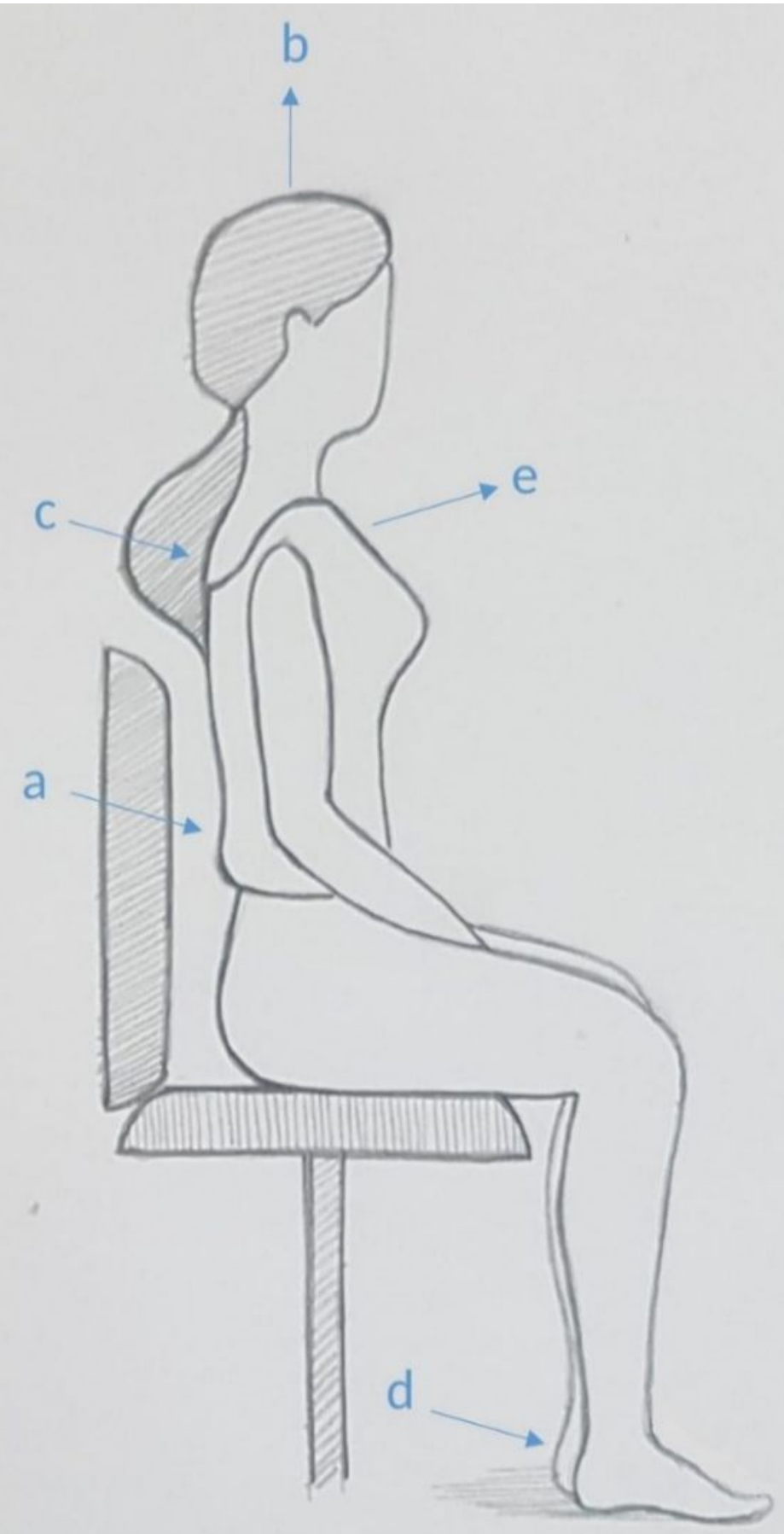

\section{Figure 2}

Participants posture during eye movement exercises or diaphragmatic breathing: $a=$ upright back; $b=$ fixed, leveled, and high-up head; $c$ = rolled backed shoulders; $d$ = planted feet on the ground at a 90-degree angle to the extension of shoulders; $\mathrm{e}=$ slouched forward breast. 

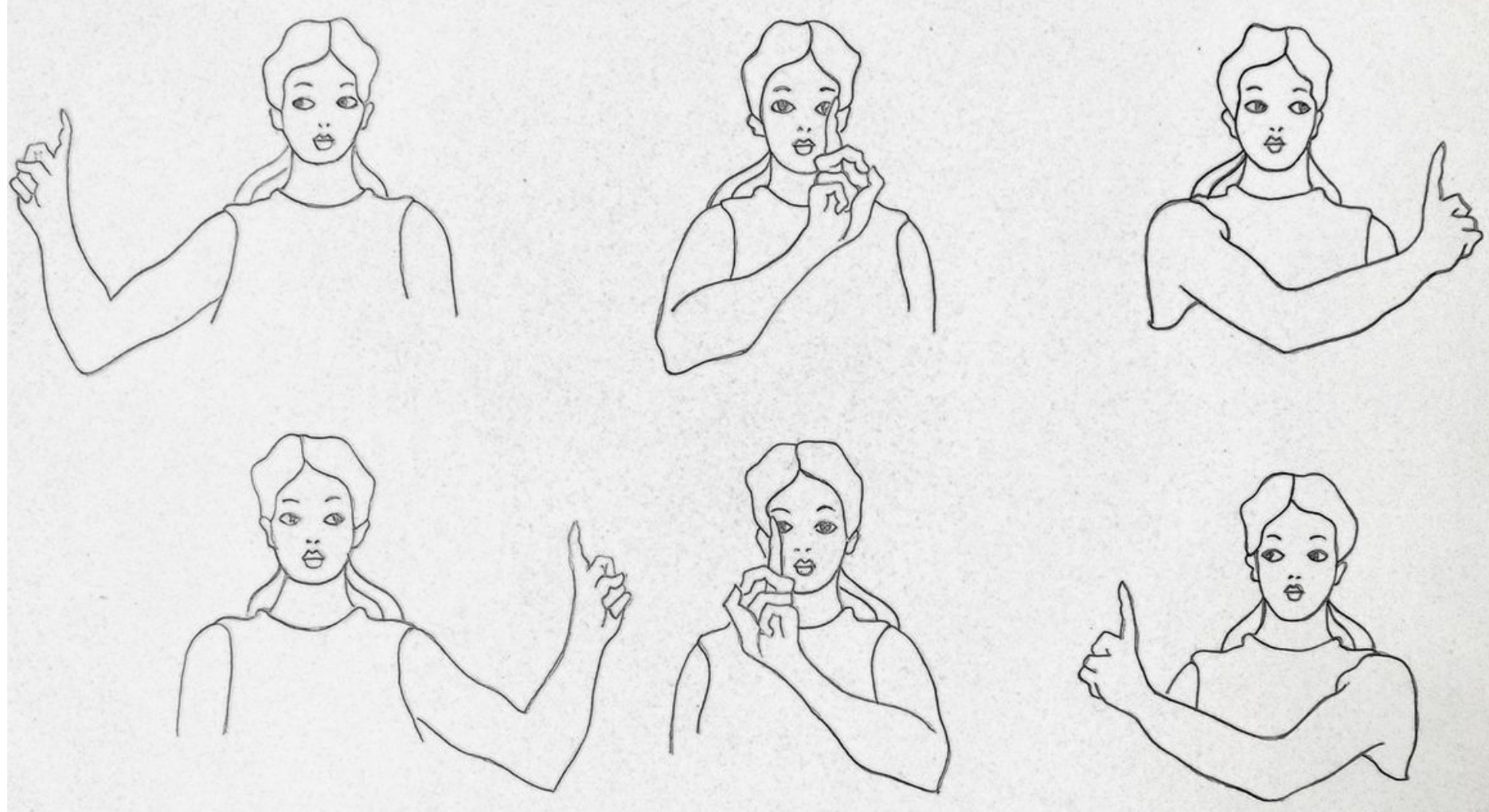

\section{Figure 3}

Shows participants eye movement exercises for experimental groups: first row shows right hand-guided eye movement exercises; second row shows left hand-guided eye movement exercises.
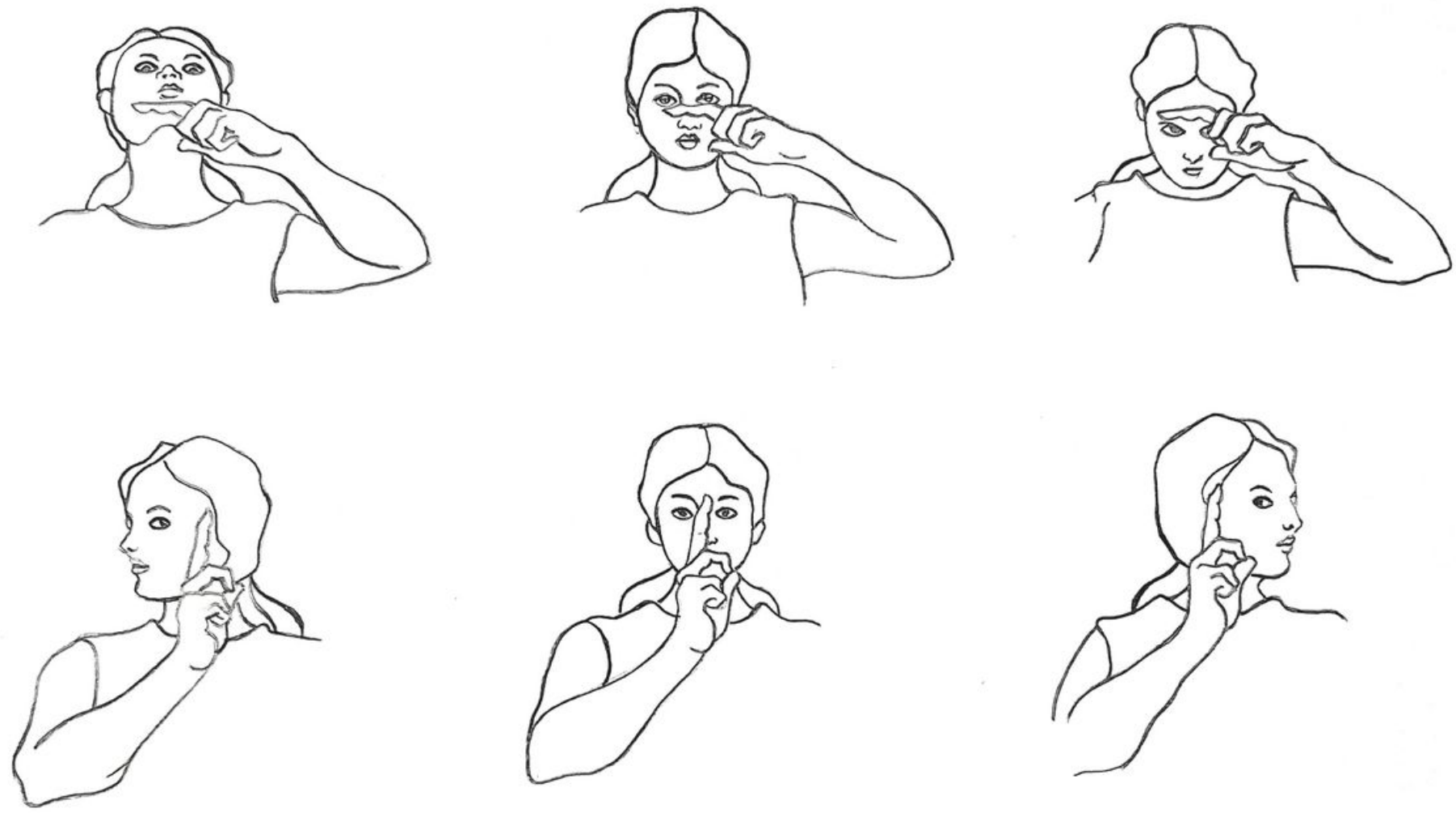
Figure 4

Shows participants eye movement exercises for experimental groups: first row shows vertical headguided eye movement exercises; second row shows horizontal head-guided eye movement exercises.

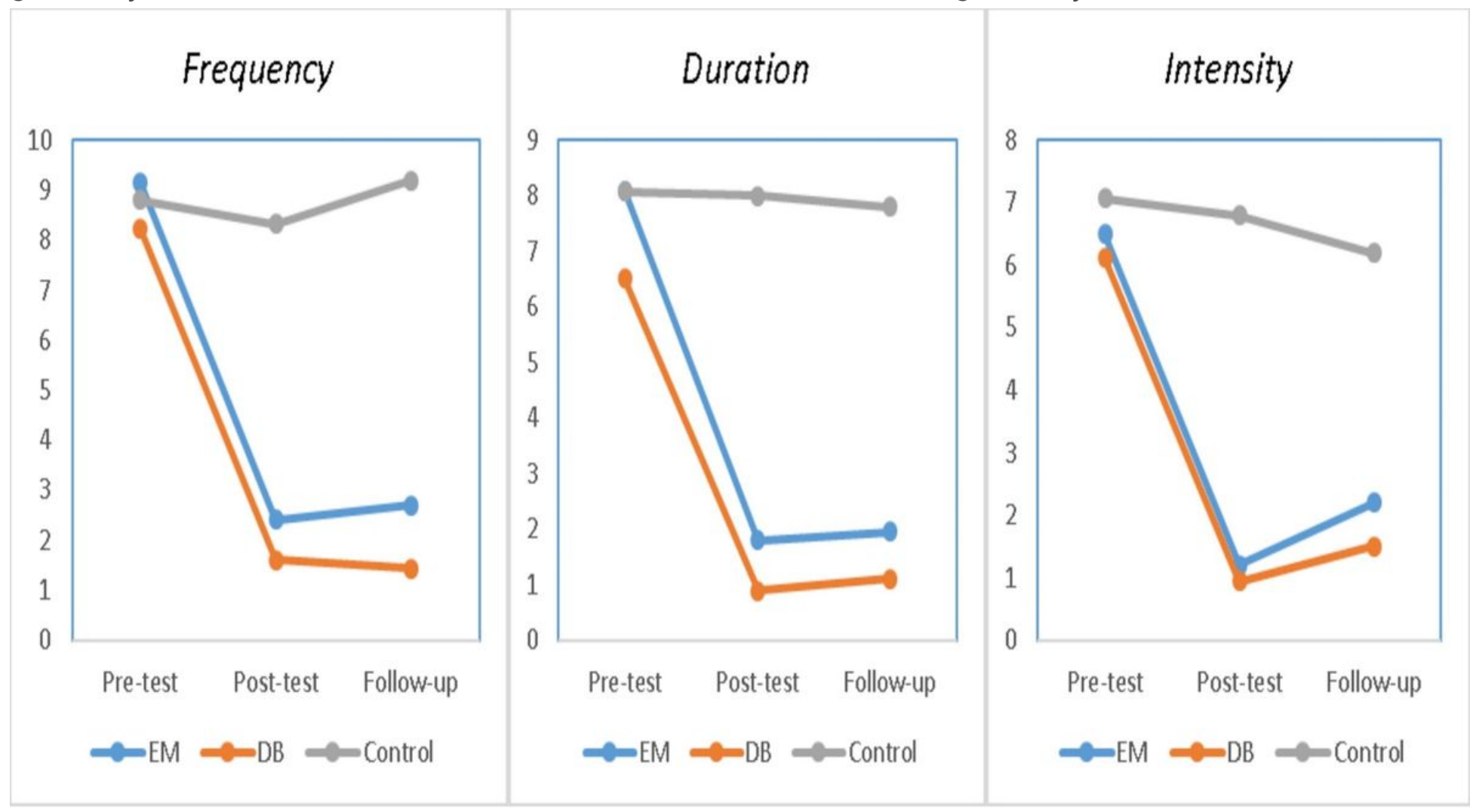

\section{Figure 5}

Migraine pain (frequency; ranges 1-9 attacks, duration; ranges 1-8 hours/attack, and intensity; ranges a scale of 1-7/attack during the last four-week) changes in each study (EM = eye movement exercises, $D B=$ diaphragmatic breathing, control) group across three assessment points (pre-test, pot-test, and followup). 